\title{
The Journey To Work: A Cross-Sectional Analysis
}

\author{
C. F. Sirmans*
}

\section{INTRODUCTION}

The literature dealing with the journey to work is quite extensive. ${ }^{1}$ However, most noticeably missing from the literature are studies of the influence of time on the journey to work. This is probably due in part to the lack of data since it wasn't until 1960 that such data were collected by the Census for the United States. ${ }^{2}$ With the availability of 1970 Census information, it is now possible to obtain crosssectional data for two time periods (1960 and 1970) of journey to work patterns for all counties in the United States.

The purpose of this paper is to analyze journey to work patterns utilizing cross-sectional data for the periods 1960 and 1970 for the Standard Metropolitan Statistical Areas in the State of Georgia. ${ }^{3}$ Through such an analysis, a basis is provided for determining trends in the journey to work. If it is possible to observe trends, a basis would be provided for predicting the journey to work in future time periods. This dynamic aspect of commuting to work patterns is particularly significant for the formulation and application of public policies.

An outline of the paper is as follows: Section II develops a probabilistic model for analyzing journey to work patterns over time. Section III contains the results of the application of the model utilizing the 1960 and 1970 cross-sectional data. Section IV contains the summary and conclusions.

\section{METHODOLOGY}

The methodology used in this paper is that of a transition probability model. Table 1 is the 1960 and 1970 employment commuting matrix for the Atlanta SMSA. This matrix is simply a "from-to" journey to work matrix and indicates the number of people commuting from one county (place of residence) to another county (place of employment). ${ }^{4}$ The data reported in Table 1 were obtained from the Census for 1960 and 1970 .

The absolute numbers reported in Table 1 yield very little information as to changes in commuting patterns over time except that total employment has increased in all areas. One observation that can be made utilizing Table 1 is that of net commuting patterns. All counties, except DeKalb-Fulton, have negative net commuting, i.e., more people journey out than in of the county for employment. The changes in net commuting patterns will be discussed later.

\footnotetext{
*Graduate Student, Department of Real Estate and Urban Development, University of Georgia, Athens, Georgia.
} 
TABLE $1^{\text {a }}$

EMPLOYMENT COMMUTING MATRIX ${ }^{\mathrm{b}}-1960$ and $1970^{\circ}$ Atlanta SMSA

\begin{tabular}{|c|c|c|c|c|c|c|c|c|}
\hline FROM- ${ }^{\text {TO- } j}$ & Clayton & Cobb & $\begin{array}{l}\text { DeKalb- } \\
\text { Fulton }\end{array}$ & Douglas & Gwinnett & Rockdale & Outside & Total \\
\hline \multirow[t]{2}{*}{ Clayton } & $(11,566)$ & $(465)$ & $(24,311)$ & $(0)$ & (115) & (7) & $(624)$ & $(37,088)$ \\
\hline & 4,772 & 122 & 10,677 & 0 & 7 & 0 & 399 & 15,977 \\
\hline \multirow[t]{2}{*}{ Cobb } & $(537)$ & $(44,639)$ & $(31,071)$ & $(250)$ & (297) & $(0)$ & (651) & $(77,445)$ \\
\hline & 48 & 27,159 & 12,781 & 0 & 11 & 0 & 916 & 40,915 \\
\hline \multirow[t]{2}{*}{ DeKalb-Fulton } & $(6,133)$ & $(10,831)$ & $(364,949)$ & $(100)$ & $(2,610)$ & $(519)$ & $(1,060)$ & $(386,202)$ \\
\hline & 2,776 & 4,243 & 284,579 & 64 & 529 & 309 & 7,127 & 299,627 \\
\hline \multirow[t]{2}{*}{ Douglas } & (105) & $(1,431)$ & $(5,136)$ & $(2,473)$ & $(22)$ & $(0)$ & (299) & $(9,466)$ \\
\hline & 26 & 718 & 2,334 & 1,927 & 0 & 0 & 281 & 5,286 \\
\hline \multirow[t]{2}{*}{ Gwinnett } & $(0)$ & $(590)$ & $(16,016)$ & (73) & $(9,400)$ & (55) & $(815)$ & $(26,949)$ \\
\hline & 30 & 187 & 6,410 & 0 & 7,094 & 0 & 951 & 14,672 \\
\hline \multirow[t]{2}{*}{ Rockdale } & (87) & (37) & $(2,925)$ & (0) & $(50)$ & $(2,834)$ & $(226)$ & $(6,159)$ \\
\hline & 40 & 13 & 955 & 0 & 0 & 2,452 & 147 & 3,607 \\
\hline \multirow[t]{2}{*}{ Outside } & $(2,974)$ & $(5,971)$ & $(23,615)$ & $(363)$ & $(1,409)$ & (906) & $(0)$ & $(35,238)$ \\
\hline & 1,621 & 3,777 & 17,303 & 85 & 607 & 353 & 0 & 23,746 \\
\hline \multirow[t]{2}{*}{ Total } & $(21,402)$ & $(63,964)$ & $(468,023)$ & $(3,259)$ & $(13,903)$ & $(4,321)$ & $(3,675)$ & $(578,547)$ \\
\hline & 9,313 & 36,219 & 335,039 & 2,076 & 8,248 & 3,114 & 9,821 & 403,830 \\
\hline
\end{tabular}

aSource: 1960 and 1970 Census of Population. The data for 1970 are also reported in Commuting Patterns 1970, prepared by the Office of Planning and Budget, Planning Division, State Demographics Data Center, State of Georgia, May 1973.

bBased on total reported.

c1970 in parentheses. 
By putting the data reported in Table 1 in the form of transition probabilities, it is possible to make some inferences about changes in journey to work patterns over the period 1960 to 1970.

\section{ANALYSIS}

Utilizing the data in Table 1, it is possible to derive Table 2 which enables some observations to be made about changes in net commuting patterns over the period 1960 to 1970 .

Table 2 indicates the ratios of in-commuting to out-commuting. These ratios were calculated by subtracting intra-county commuting and dividing the total incommuting in Table 1 by the total out-commuting. These ratios indicate in-commuting pattern changes for 1960 and 1970 (in parentheses).

A ratio of one indicates that there is zero net commuting, i.e., in-commuting equals out-commuting. A ratio greater than one indicates that there is positive net commuting, i.e., in-commuting is greater than out-commuting. Likewise, a ratio less than one indicates negative net commuting, i.e., in-commuting is less than out-commuting.

TABLE $2^{\mathrm{a}}$

COMMUTING RATIOS

1960-1970

Atlanta SMSA

Total

In-Commuting

\begin{tabular}{lccc}
\hline Clayton & $(9,836)$ & $(25,522)$ & $(.3854)$ \\
& 4,541 & 11,205 & .4053 \\
\hline Cobb & $(19,325)$ & $(32,806)$ & $(.5891)$ \\
& 9,060 & 13,756 & .6586 \\
\hline DeKalb-Fulton & $(103,074)$ & $(21,251)$ & $(4.8503)$ \\
& 50,460 & 15,048 & 3.3533 \\
\hline Douglas & $(786)$ & $(6,993)$ & $(.1124)$ \\
& 149 & 3,359 & .0444 \\
\hline Gwinnett & $(4,503)$ & $(17,549)$ & $(.2566)$ \\
& 1,154 & 7,578 & .1523 \\
\hline Rockdale & $(1,487)$ & $(3,325)$ & $(.4472)$ \\
& 662 & 1,155 & .5732 \\
\hline Outside & $(3,675)$ & $(35,238)$ & $(.1043)$ \\
& 9,821 & 23,746 & .4136 \\
\hline
\end{tabular}

aSource: Derived from Table 1.

bIntra-county commuting not included.

c1970 in parentheses. 
As indicated only the DeKalb-Fulton area had positive net commuting patterns. The ratios also indicate that in-commuting increased for DeKalb-Fulton since the ratio increased from 1960 to 1970 . The ratios also indicate that in-commuting relative to out-commuting in two other counties (Douglas and Gwinnett) increased during the decade. However, these two areas still have negative net commuting patterns.

The in-commuting for all of the other counties decreased over the decade indicating that more people were commuting out to work.

Table 3 is a matrix of commuting transition probabilities. ${ }^{5}$ The transition probabilities were calculated from Table 1 by dividing the employment in each cell by the total reported employment by place of residence. This relationship can be expressed by the following equation:

$$
P_{i j}=\frac{E_{i j}}{T R_{i}}
$$

where

$$
\begin{aligned}
\mathrm{P}_{\mathrm{ij}}= & \begin{array}{l}
\text { the probability of being employed in county } \mathrm{j} \text { given place } \\
\text { of residence in county } \mathrm{i} \text { (the proportion of total employment } \\
\text { residing in county } \mathrm{i} \text { that is employed in county } \mathrm{j} \text { ). }
\end{array} \\
\mathrm{E}_{\mathrm{ij}}= & \text { employment in county } \mathrm{j} \text { given county } \mathrm{i} . \\
\mathrm{TR}_{\mathrm{i}}= & \begin{array}{l}
\text { total reported out-commuting from county } \mathrm{i} \text { (the total } \\
\text { reported employment living in county } \mathrm{i} \text { ). }
\end{array}
\end{aligned}
$$

Thus, the probabilities sum to one across the rows.

Each probability, $\mathrm{P}_{\mathrm{ij}}$, is the probability of transition (commuting to work) from a particular state, $i$, to another state, $j$. This probability is uniquely determined by the state in which the system is located. These transition probabilities represent the probability of living in one county and being employed in another (or the same) county.

The matrix of commuting transition probabilities (Table 3) indicates the commuting patterns for time periods 1960 and 1970. The probabilities for 1970 are in parentheses. The changes in commuting transition probabilities are presented in Table 4.

Along the main diagonal of Table 3 are the probabilities of intra-commuting. These represent the probability of any particular worker being employed in the same county in which he resides. The results indicate that more people are commuting outside their county of residence for employment in 1970. Only one county (Clayton) indicated a greater probability of living in the same county as the county of employment (represented by positive change in Table 4). 
TABLE $3^{\mathrm{a}}$

OUT-COMMUTING TRANSITION PROBABILITIES ${ }^{\mathrm{b}}-1960$ and $1970^{\circ}$

Atlanta SMSA

\begin{tabular}{|c|c|c|c|c|c|c|c|c|}
\hline From-i ${ }^{\text {To-j }}$ & Clayton & Cobb & $\begin{array}{l}\text { DeKalb- } \\
\text { Fulton }\end{array}$ & Douglas & Gwinnett & Rockdale & Outside & Total \\
\hline \multirow[t]{2}{*}{ Clayton } & $(.3119)$ & $(.0125)$ & $(.6555)$ & $(.0000)$ & $(.0031)$ & $(.0002)$ & $(.0168)$ & $(1.0000)$ \\
\hline & .2987 & .0076 & .6683 & .0000 & .0004 & .0000 & .0250 & 1.0000 \\
\hline \multirow[t]{2}{*}{ Cobb } & $(.0069)$ & $(.5764)$ & $(.4012)$ & $(.0032)$ & $(.0039)$ & $(.0000)$ & $(.0084)$ & $(1.0000)$ \\
\hline & .0012 & .6638 & .3123 & .0000 & .0003 & .0000 & .0224 & 1.0000 \\
\hline \multirow{2}{*}{ DeKalb-Fulton } & $(.0159)$ & $(.0280)$ & $(.9450)$ & $(.0003)$ & $(.0068)$ & $(.0013)$ & $(.0027)$ & $(1.0000)$ \\
\hline & .0092 & .0141 & .9500 & .0002 & .0017 & .0010 & .0238 & 1.0000 \\
\hline \multirow{2}{*}{ Douglas } & $(.0111)$ & $(.1512)$ & $(.5425)$ & $(.2613)$ & $(.0023)$ & $(.0000)$ & $(.0316)$ & $(1.0000)$ \\
\hline & .0049 & .1358 & .4416 & .3645 & .0000 & .0000 & .0532 & 1.0000 \\
\hline \multirow{2}{*}{ Gwinnett } & $(.0000)$ & $(.0219)$ & $(.5943)$ & $(.0027)$ & (.3488) & $(.0021)$ & $(.0302)$ & $(1.0000)$ \\
\hline & .0020 & .0128 & .4369 & .0000 & .4835 & .0000 & .0648 & 1.0000 \\
\hline \multirow{2}{*}{ Rockdale } & $(.0141)$ & $(.0060)$ & $(.4749)$ & $(.0000)$ & $(.0081)$ & $(.4602)$ & $(.0367)$ & $(1.0000)$ \\
\hline & .0110 & .0036 & .2648 & .0000 & .0000 & .6798 & .0408 & 1.0000 \\
\hline \multirow{2}{*}{ Outside } & $(.0844)$ & $(.1694)$ & $(.6702)$ & $(.0103)$ & $(.0400)$ & $(.0257)$ & $(.0000)$ & $(1.0000)$ \\
\hline & .0683 & .1591 & .7286 & .0036 & .0255 & .0149 & .0000 & 1.0000 \\
\hline \multirow[t]{2}{*}{ Total } & $(.0370)$ & (.1105) & $(.8090)$ & $(.0056)$ & $(.0240)$ & $(.0075)$ & $(.0064)$ & $(1.0000)$ \\
\hline & .0231 & .0897 & .8297 & .0051 & .0204 & .0077 & .0243 & 1.0000 \\
\hline
\end{tabular}

aSource: 1960 and 1970 Census of Population. The data for 1970 are also reported in Commuting Patterns 1970, prepared by the Office of Planning and Budget, Planning Division, State Demographics Data Center, State of Georgia, May 1973.

bBased on total reported.

c1970 in parentheses. 
TABLE $4^{\mathrm{a}}$

\section{COMMUTING TRANSITION PROBABILITIES}

Changes - 1960 to 1970

Atlanta SMSA

\begin{tabular}{lcccccccc} 
& & & DeKalb- & & & \\
FROM- i & Clayton & Cobb & Fulton & Douglas & Gwinnett & Rockdale & Outside & Total \\
\hline Clayton & .0132 & .0049 & -.0128 & .0000 & .0027 & .0002 & -.0082 & .0000 \\
\hline Cobb & .0057 & -.0874 & .0889 & .0032 & .0036 & .0000 & -.0140 & .0000 \\
\hline DeKalb-Fulton & .0067 & .0139 & -.0050 & .0001 & .0051 & .0003 & -.0211 & .0000 \\
\hline Douglas & .0062 & .0154 & .1009 & -.1032 & .0023 & .0000 & -.0216 & .0000 \\
\hline Gwinnett & -.0020 & .0091 & .1574 & .0027 & -.1347 & .0021 & -.0346 & .0000 \\
\hline Rockdale & .0031 & .0024 & .2101 & .0000 & .0081 & -.2196 & -.0041 & .0000 \\
\hline Outside & .0161 & .0103 & -.0584 & .0067 & .0145 & .0108 & .0000 & .0000 \\
\hline Total & .0139 & .0208 & -.0207 & .0005 & .0036 & -.0002 & -.0179 & .0000 \\
\hline
\end{tabular}


The intra-county probabilities of the remaining six counties indicate that from 1960 to 1970 there has been a decrease in the probability of residing in the same county as employed. These decreases in intra-county probabilities range from a low of -.005 for DeKalb-Fulton to a high of -.2196 for Rockdale County as indicated in Table 4.

The probabilities not along the main diagonal indicate the probability of inter-county commuting. In every case except two the probabilities of inter-county commuting increased as shown by positive increases in Table 4 . These increases indicate that employment for the Atlanta SMSA has become more dispersed during the decade 1960-1970. This is obvious by looking at the total row. The total row indicates the proportion of total employment contained in each area. All probabilities of in-commuting to each of the counties have increased except for DeKalb-Fulton. This indicates that the DeKalb-Fulton area had less of the total employment for the Atlanta SMSA in 1970. However, as noted earlier, DeKalbFulton is still the only county in which net commuting is positive; all other counties have negative net commuting patterns.

Another conclusion that can be drawn is that there is a smaller probability of commuting to outside the SMSA since all probabilities in the outside column decreased over the decade 1960-1970. Along the outside row (the probability of commuting from the outside into the SMSA) all probabilities increased, except DeKalb-Fulton, indicating that there is a greater probability of living outside the area and commuting into it.

The equilibrium transition probabilities are along the total row in Table 3. These represent that proportion of total employment which is obtained by each county. These probabilities indicate that the commuting into each county has increased during the decade 1960 to 1970 except for the DeKalb-Fulton area.

The journey to work transition probabilities can be analyzed in an alternative method as indicated by equation (2). These transition probabilities, as shown in Table 5, represent the probability of commuting into (rather than from) county $\mathrm{j}$ given place of residence in county $\mathrm{i}$ and were calculated as follows:

$$
P_{i j}=\frac{E_{i j}}{T R I_{j}}
$$

where

$$
\begin{aligned}
& P_{i j}=\text { probability of commuting into state } \mathrm{j} \text { given place } \\
& \text { of residence } i \text { (the proportion of total employed in county } \\
& j \text { which resides in county } i \text { ). } \\
& \mathrm{E}_{\mathrm{ij}}=\text { employment in county } \mathrm{j} \text { given county } \mathrm{i} \text {. } \\
& \text { TRI }_{j}=\text { total reported in-commuting to state } j \text { (the total } \\
& \text { reported employment working in state } j \text { ). }
\end{aligned}
$$

Thus, the probabilities sum to one down the columns. 
TABLE $5^{\mathrm{a}}$

IN-COMMUTING TRANSITION PROBABILITIES ${ }^{\text {b }}$ Atlanta SMSA

\begin{tabular}{|c|c|c|c|c|c|c|c|c|}
\hline FROM- $\mathrm{i}^{\text {TO- } \mathrm{j}}$ & Clayton & Cobb & $\begin{array}{l}\text { DeKalb- } \\
\text { Fulton }\end{array}$ & Douglas & Gwinnett & Rockdale & Outside & Total \\
\hline \multirow[t]{2}{*}{ Clayton } & $(.5404)$ & $(.0073)$ & $(.0519)$ & $(.0000)$ & $(.0083)$ & $(.0016)$ & $(.1698)$ & $(.0641)$ \\
\hline & .5124 & .0034 & .0319 & .0000 & .0008 & .0000 & .0406 & .0396 \\
\hline \multirow[t]{2}{*}{$\mathrm{Cobb}$} & $(.0251)$ & $(.6979)$ & $(.0664)$ & $(.0767)$ & $(.0214)$ & $(.0000)$ & $(.1771)$ & $(.1339)$ \\
\hline & .0052 & .7499 & .0381 & .0000 & .0013 & .0000 & .0933 & .1013 \\
\hline \multirow[t]{2}{*}{ DeKalb-Fulton } & $(.2865)$ & $(.1693)$ & $(.7797)$ & $(.0307)$ & $(.1877)$ & $(.1201)$ & $(.2884)$ & $(.6675)$ \\
\hline & .2980 & .1170 & .8494 & .0308 & .0642 & .0992 & .7257 & .7420 \\
\hline \multirow[t]{2}{*}{ Douglas } & $(.0049)$ & $(.0224)$ & $(.0110)$ & $(.7588)$ & $(.0016)$ & $(.0000)$ & $(.0814)$ & $(.0164)$ \\
\hline & .0028 & .0198 & .0070 & .9282 & .0000 & .0000 & .0286 & .0131 \\
\hline \multirow[t]{2}{*}{ Gwinnett } & $(.0000)$ & $(.0092)$ & $(.0342)$ & $(.0224)$ & $(.6761)$ & $(.0127)$ & $(.2218)$ & $(.0466)$ \\
\hline & .0032 & .0052 & .0191 & .0000 & .8601 & .0000 & .0968 & .0363 \\
\hline \multirow[t]{2}{*}{ Rockdale } & $(.0041)$ & $(.0006)$ & $(.0062)$ & $(.0000)$ & $(.0036)$ & $(.6559)$ & $(.0615)$ & $(.0106)$ \\
\hline & .0043 & .0004 & .0029 & .0000 & .0000 & .7874 & .0150 & .0089 \\
\hline \multirow[t]{2}{*}{ Outside } & $(.1390)$ & $(.0933)$ & $(.0505)$ & $(.1114)$ & $(.1013)$ & $(.2097)$ & $(.0000)$ & $(.0609)$ \\
\hline & .1741 & .1043 & .0516 & .0410 & .0736 & .1134 & .0000 & .0588 \\
\hline \multirow[t]{2}{*}{ Total } & $(1.0000)$ & $(1.0000)$ & $(1.0000)$ & $(1.0000)$ & $(1.0000)$ & $(1.0000)$ & $(1.0000)$ & $(1.0000)$ \\
\hline & 1.0000 & 1.0000 & $1.0000^{\prime}$ & .1 .0000 & 1.0000 & 1.0000 & 1.0000 & 1.0000 \\
\hline
\end{tabular}


The numbers in Table 5 are the proportions of the total employment working in a given county $\mathrm{j}$ by place of residence in county $\mathrm{i}$. Again, along the main diagonal are the probabilities of intra-county commuting. In every case (except one) the proportions of total employment which are employed in the county of residence decreased.

The proportions not along the main diagonal represent the inter-county journey to work patterns. Again, the trend from 1960 to 1970 was an increase in inter-county patterns as indicated by increased proportions.

Table 5 indicates that the proportion of the persons employed from the outside decreased for three counties and increased for three counties as seen along the total row. The total column in Table 5 indicates the proportion of total employment which resides inside the Atlanta SMSA. These proportions have increased in every case between 1960 and 1970 except for DeKalb-Fulton which decreased.

\section{CONCLUSIONS}

The purpose of this paper was to analyze the journey to work patterns using cross-sectional data for the periods 1960 and 1970. The analysis provides a basis for determining trends and possibly projecting the journey to work patterns in future time periods. Such an analysis, however, is beyond the scope of the present paper.

The data indicated that there was a decrease in the intra-county commuting, i.e., more people were employed outside their county of residence. The results also indicated that the inter-county patterns increased.

\section{FOOTNOTES}

1 For a review of the journey to work literature, see John F. Kain, "Urban Travel Behavior," in Urban Research and Policy Planning, edited by Leo F. Schnore and Harry Fagin, Urban Affairs Annual Reviewers, Sage Publications, Inc., Beverly Hills, California, 1967, pp. 161-192. Also, see A. M. Warnes, "Estimates of Journey to Work Distances from Census Statistics," Regional Studies, Vol. 6, No. 2, 1972, pp. 315-326.

2 The data are not in the written reports but are contained on Census tapes and were based on a $25 \%$ sample for 1960 and a $15 \%$ sample for 1970. For a discussion of sources of commuting data, see Leo F. Schnore, "Three Sources of Data on Commuting: Problems and Possibilities," American Statistical Association Journal, Vol. 55, 1960, pp. 8-22.

3Other areas were tested but due to limited space only the results for the Atlanta SMSA are reported The same general conclusions can be drawn for the other areas. In the matrix for the Atlanta SMSA, De$\mathrm{Kalb}$ and Fulton Counties were combined in the 1960 data. Thus to be consistent and to enable comparisons these two counties were treated as one area in 1970.

4The data shown in Table 1 are based on total reported employment.

${ }^{5}$ At first glance the journey to work problem might appear as a Markov Chain. However, one of the key properties for Markov analysis is lacking, that of stationary transition probabilities. One aspect of the technique of Markov analysis, the transition probabilities, does provide a useful starting point for analysis as pointed out by L. A. Brown, "On the Use of Markov Chains in Movement Research," Economic Geography, Vol. 6, No. 2, June 1971, pp. 393-403. 